\title{
Imposto sobre operação relativa à circulação de mercadorias.
}

Ruy Barbosa Nogueira

\author{
Catedrático de Direito Tributário e Profes- \\ sor de Direito Tributário Comparado na \\ Faculdade de Direito da Universidade de \\ São Paulo. Advogado em São Paulo.
}

\begin{abstract}
SUMARIO: Atribuições de Oficio e Vinculadas da Fiscalização. Obrigaçôes acessórias e deveres de colaboração para-fiscalizadora dos Próprios Contribuintes e seus Limites. Exemplo do Caso de Sucata e Semelhantes, cujo Controle Fiscal é prima-facie Difícil para a Própria Administração Fiscal. Infração Meramente Formal e Pagamento Efetivo do Imposto não Cumulativo ou de Valor Acrescido. Análise Crítica de Decisão de Primeira Instância e Correção dos Excessos pela Equidistância do Egrégio Tribunal de Imposto e Taxas.
\end{abstract}

O FATO OBJETO DESTE ESTUDO.

Uma empresa comercial (A) fez três compras de sucata de meıal, a um comerciante desses resíduos (B), exigindo de $\mathrm{B}$ a respectiva documentação e entrega desse material a um estabelecimento industrializador (c), ao qual encomendara a industrialização da sucata.

* Este é um exemplo concreto de como estamos realizando os estudos de Casos e Problemas nos Cursos de Graduação, Especialização, Mestrado, Doutorado e nas Mesas de Debates, na Faculdade de Direito do Largo de São Francisco, de acordo com os novos Estatutos da USP. Além do programa e bibliografia que distribuimos, utilizamos os livros de texto (Curso de Direito Tributário e Direito Tributário Comparado) e as Coletâneas de "Casos Tributários" (1." a 5."). Sempre que possível, antes de publicarmos um trabalho sobre caso concreto, apresentamo-lo aos alunos, conforme o grau do curso, mas apenas "O Fato Objeto do Estudo". Somente depois de os alunos, motivados pelas dúvidas, terem estudado, 
Entendendo que o estabelecimento fabril recolhesse o respectivo débito do ICM, no entanto " $\mathrm{C}$ " the devolveu a sucata devidamente industrializada, com suspensão do ICM .

Todavia a empresa comercial "A", ao vender os produtos industrializados por " $\mathrm{C}$ ", recolheu efetiva e integralmente o ICM sobre o valor das mercadorias.

Em consequiência de atos especiais de fiscalização, a administração constatou que o vendedor de sucata procedera, em outras operações, com dolo.

Autuada a empresa "A", esta provou por farta documentação, mediante certidões e documentos fiscais, que exigira toda a documentação com os requisitos legais.

No entanto, o julgador tributário de primeira instância, proferiu no caso a seguinte decisão:

"Autuado por haver transacionado com firma inexistente sob aspecto fiscal, bem como pela falta de recolhimento do imposto pela aquisição de sucatas, o contribuinte apresentou defesa que constitui fls. 25 a 94

No que concerne à acusação contida no item "a" do auto, trata-se mais de um relacionado com a aquisição de sucatas, com firmas inexistentes de fato, apesar de, formalmente, exigir notas fiscais, pretendendo com isso demonstrar a inexistência regulamentar do vendedor. Em que possam pesar as razōes da defendente, o que ressalta de importância é que a exigência da ficha de inscrição e o aspecto exterior, formal, dos documentos, não são suficientes para eximir o contribuinte de responsabilidade, nos casos da espécie.

Bem de ver que, além das exigências formais, o contribuinte que comercia com "desconhecidos" assume responsabilidade por situações que

debatido ou pelo menos se preparado, é que apresentamos a "Problemática, Estud̃o e Conclusão do Caso Exposto", para novo debate, confronto e critica com os trabalhos que cada um ou a equipe tenha realizado. Este tipo de estudo é o que recomendamos à p. 255 do livro Direito Financeiro - Curso de Direito Tributário, 3. ${ }^{a}$ edição, 1971. O desenvolvimento desta metodologia socrática, como verdadeiro "laboratório jurídico", vem apresentando resultados muito satisfatórios. 
possam decorrer. Não justifica ninguém o fato de transacionar com alguém que não possue tradição comercial, isto é, com firmas desconhecidas do adquirente. Constitui providência de cautela saber com quem se comercia, máximo se uma das partes se apresenta como contribuinte localizado em outro Município. Além do mais, as verificações de profundidade efetuadas pela fiscalização, conforme documentação anexa às fls. 3 a 18, esclarece suficientemente que o devedor ou seja emitente das notas fiscais de fls. 20 a 22 , o senhor .... transacionou simplesmente "notas frias".

No que tange à acusação contida no item " $b$ ", o autuado ao transformar sucata em produto industrializado ainda que por intermédio de terceiro, configura-se como industrializador, sujeito portanto ao recolhimento do ICM — de acordo com o artigo $2 .^{\circ}$, do Decreto 50.971/68, uma vez que a Laminação . é no caso presente, simples prestador de serviços.

Assim todas as razões apresentadas pela defesa, não são suficientes para eximi-la da responsabilidade, "in casu", quando se trata, inclusive de falta de recolhimento de imposto.

Em face do exposto, julgo procedente o auto de infração de fls. 2, lavrado por infringência aos artigos $2 .^{\circ}$, do Decreto 50.971/68, 39, 40, 37, 98 e 104, do Decreto $47763 / 67$, e confirmo a multa imposta no total de $\mathrm{Cr} \$$.... sem prejuízo do recolhimento do imposto na importância de Cr\$ .. . . A multa acima, foi graduada de acordo com o disposto nos incisos I e XVI, do art. 158, do Decreto n. $.^{\circ} 47.763 / 67$, modificados respectivamente pelos artigos 13 do Decreto 52.666/71 e art. 18 , do Decreto $52.103 / 69$.

À vista do processo, cujo xerox se exibe, essa decisão ora suscetível de recurso voluntário ao T.I.T é procedente? Quais são no caso os limites das obrigações acessórias das empresas adquirentes, dentro do contexto da legislação vigente? A obrigação principal (pagamento do imposto) foi efetivamente cumprida? Qual a solução jurisdicional que deve ser pleiteada para o caso? Elaborar razões de Recurso Voluntário ao T.I.T. 
PROBLEMATICA, ESTUDO E CONCLUSÃO DO CASO EXPOSTO. (Razões de recurso)

I. Além do pagamento de tributos, dos trabalhos de arrecadação e da mole ingente de serviços burocráticos ${ }^{1}$ que, como obrigação e colaboração as empresas contribuintes prestam ao Fisco, dentro da necessária harmonia e boas relações que devem existir entre Fisco e Contribuinte, o texto da legislação exige dos bons contribuintes, como o máximo possível na colaboração à fiscalização, tão só, o seguinte, que está no RICM:

"Art. 104 - Sempre que fôr obrigatória a emissão de documentos fiscais, aqueles a quem se destinarem as mercadorias são obrigados a exigir tais documentos dos que devam emitílos, contendo todos os requisitos legais".

II. Pois bem. A ora recorrente não só exigiu tais documentos do comerciante com depósito de sucata, por ocasião das poucas compras que the fez mas; instaurado o processo, foi ainda buscar e juntar aos autos todas as certidões de inscrição fornecidas pela própria Fazenda do Estado, pelas Fazendas Federal e Municipal e notas da vendedora e da empresa fabricante e provou inclusive as quantidades reais.

III. Ora, esta empresa não podia, como não pode, ser obrigada à prática de atos de "fiscalização em profundidade" contra a empresa comercial vendedora, estabelecida e inscrita como contribuinte (denominação Sucatas de Metais Ferrosos e Não Ferrosos em Geral ... firma individual. .).

Em primeiro lugar porque a Constituição vigente, dispondo sobre os direitos e garantias individuais the proíbe uma tal incursão, dispondo no art. $153, \S 99^{\circ}$ que "é inviolável o sigilo da correspondência" e os artigos 17 e 18 do Código Comercial protegem, contra as demais empresas ou particulares, o sigilo dos livros daquela empresa comercial.

1. Vide nosso trabalho Burocratização Fiscal das Atividades Privadas in Fisco e Contribuinte, 1967, p. 560 e com mais desenvolvimento, em nosso Livro Teoria do Lançamento Tributário, edição Revista dos Tribunais, S. Paulo, 1965, p. 228 e 241. 
Em segundo lugar porque é somente a fiscalização que, remunerada pelos cofres públicos, tem essa função. Especialmente os artigos 195 a 200 do C.T.N. é que concedem à Fiscalização não só o direito ao exame ou fiscalização dos livros e documentos, mas dá-lhe a instrumentalidade; as cautelas; a assistência mútua entre os vários fiscos e também a função "ex officio"; a fé pública; a obrigação vinculada e, se necessária, até a força policial (art. 200 do CTN) para esse exercício do poder público.

IV. Como se vê do texto específico do art. 104 do RICM, o máximo que a legislação determinou à ora recorrente foi:

"exigir tais documentos dos que devam emitílos, contendo todos os requisitos legais".

Isto é, todos os requisitos extrínsecos, devidamente explicitados por escrito nos documentos produzidos sob a responsabilidade dos respectivos emitentes, autores ou produtores desses documentos.

V O ilustre Julgador Tributário da $1 .^{\mathrm{a}}$ instância, entretanto, desconhecendo ou descurando-se não só da legislação estadual (art. 104 do RICM); da Constituição (art. 153, § 9. ${ }^{\circ}$ ); do Código Comercial (arts. 17 e 18), mas do próprio C.T.N. com todo seu capítulo sobre a Fiscalização (arts. 194 a 200) e sobre a competência privativa, obrigatória e vinculada da administração para o lançamento (C.T.N , art. 142 e parágrafo único) dá como fundamentos, não só para exigir imposto, mas para aplicar multa cumulativa à suplicante, o que?

VI. Vendo que a prova legal, a reiterada e maciça prova que a ora recorrente carreou para os autos, mediante certidões e inscriçóes da Junta Comercial do Estado, da Fazenda estadual e das demais Fazendas, e todo o documentário ou notas fiscais emitidos por escrito e com todos os requisitos extrínsecos, pela firma vendedora como comerciante de sucata e contribuinte inscrita; vendo que tudo isto prova que a ora recorrente compriu religiosamente todas as suas obrigações fiscais; no entanto, o Julgador Tributário de $1 .^{\mathrm{a}}$ instância, contra toda a legislação, contra todo o jus in civitate positum, confessa e reconhece que o comerciante de sucata tinha existência legal, mas que "as verificações de profundidade efetuadas pela Fiscaalização" puderam constatar que intrinsecamente a documentação do sucateiro não seria de fato válida! 
VII. São palavras textuais da decisão recorrida, dadas como premissas da condenação:

"apesar de, formalmente existir notas fiscais, pretendendo com isso demonstrar a existência regulamentar do vendedor. Em que possam pesar as razões da defendente o que ressalta de importância é que a exigência da ficha de inscrição e o aspecto exterior, formal dos documentos, não são suficientes para eximir o contribuinte de responsabilidade, nos casos da espécie"

VIII. Ora, o ilustre Julgador, como se vê, não aponta como não pode apontar, nenhum texto de lei que mande exigir mais do que a ficha de inscrição e o documentário fiscal com todos os requisitos legais, isto é, formalizados, perpetuados por escrito ou de maneira extrínseca.

IX. Veja-se que o ilustre Julgador já nesse passo é mais realista do que o próprio Rei: ultrapassou e exacerbou as exigências expressas e específicas da lei fiscal (do RICM)!

X. - Mas não é só. Continuando sempre fora da juridicidade e da própria jurisdicidade (como julgador só emitiu juízos "obiter dicta") ${ }^{2}$ e; como se fora legislador que desconhece a própria Constituição, passou a exigir do contribuinte mais do que "o exercício regular do direito" individual e afrontando o Estatuto do Contribuinte (que já é tão restrito), passa para um verdadeiro edito das príscas eras romanas, pois esquecido de que o Brasil é uma unidade territorial e que a Constituição já aboliu as fronteiras alfandegárias ou fiscais entre cidades, pretende editar e aconselhar:

"Bem de ver que, além das exigências formais o contribuinte que comercia com "desconhecidos" assume

2. Como ressalta um dos grandes juristas da atualidade, KARL ENGISH, no magnífico livro Einführung in das juristische Denken (Introdução ao Pensamento Jurídico) 3. ${ }^{2}$ edição, 1964, Verlag Kohlhammer, Stuttgart, no capítulo VIII, uma regra jurídica expressa numa decisão é "apenas vinculativa na medida em que foi necessária para a decisão do caso jurídico; se ela é concebida com maior amplitude do que a necessária, não constitui nessa parte uma ratio decidendi decisiva, mas antes um obiter dictum irrelevante... do juiz". 
responsabilidade por situações que possam decorrer. Não justifica ninguém o fato de transacionar com alguém que não possue tradição comercial, isto é, com firmas desconhecidas do adquirente ${ }^{3}$ Constitui providência de cautela saber com quem se comercia, máxime se uma das partes se apresenta como contribuinte localizado em outro município. Além do mais, as verificações de profundidade efetuadas pela fiscalização, conforme documentação anexa às fls. 3 a 18 , esclarece suficientemente que o devedor ou seja emitente das notas fiscais de fls. 20 a 22 , o senhor transacionou simplesmente "notas frias".

XI. Se a "fiscalização em profundidade" constatou que em outras transações que não esta dos autos, aquele indivíduo operou com "notas frias", a esmagadora prova destes autos demonstra a lisura e correção da ora recorrente, pois está precisamente provado, aqui nestes autos, que as transações com a ora recorrente foram reais, não fictícias, com prova absoluta das quantidades e pesos matemáticos das mercadorias. Todos os documentos foram exigidos e nenhuma nota fria foi sonhada ou admitida no caso dos autos.

As referências a outras possíveis transações irregulares daquele indivíduo além de desconhecidas pela ora recorrente são referências indevidas nestes autos. Se em outras transações, com outras pessoas, não foi emitido o documentário e não existiu sucata, a ora recorrente, ao revérso deve ser citada como exemplo de empresa correta que tudo exigiu e por isso mesmo ficou imune de qualquer contágio. Tendo exigido todos os documentos, foi ela apenas defensora da legalidade.

XII. E interessante declarar a V Exas., Ilustrados Magistrados, que o advogado signatário já havia exposto o acima, quando em sua pesquisa encontrou a magnífica decisão unânime desta Côrte, proferida no

3. Observe-se que a teoria do ilustre julgador pretende "in limine" destruir o princípio constitucional que está no pórtico do Título III da Constituição da Repriblica Federativa do Brasil, (Da Ordem econômica e social) e que tendo por fim realizar "o desenvolvimento nacional e a justiça social", começa por garantir a "liberdade de iniciativa" (art. 160, I), pois ele não admite que ninguém mais possa começar; o mundo dos negócios será agora só para os antigos, os tradicionais, ninguém mais, a vida parou! 
Proc. DRT-1-107.053/69, na sessão de 12/1/72 e representa sedimentação do verdadeiro critério legal, jurídico e justo e que deve ser divulgado para se evidenciar o nobilitante trabalho desta Côrte:

"E preciso que se estabeleça um sistema de cumprimento rígido da norma tributária; pois sobre ela está baseada toda a segurança de uma sociedade. Porém, é também de se lembrar que não poderá a autoridade fazendária situar-se numa posição mais cômoda de atribuir ao contribuinte toda e qualquer responsabilidade de terceiros. Com isto quer dizer que se o $\mathrm{Sr}$. . . é inscrito ou foi nesta Secretaria da Fazenda, se possuía contrato social ou se agia como firma individual, estava ele legalmente apto a exercer o comércio. Não cabe ao contribuinte verificar se os documentos apresentados por ele são legítimos ou não; não cabe à Secretaria da Fazenda lançar aos ombros do contribuinte a obrigação de verificar aquilo que a ela caberia fazer. Se este Senhor não recolheu o tributo a ele deveria ser dirigida a sanção e não àqueles que, eventualmente comerciaram com ele".

XIII. Mas ainda não é só.

A decisão passa no caso "sub judice" à questão do próprio imposto, que afinal a ora recorrente já pagou integral e efetivamente, ao vender as mercadorias.

Todavia vejamos também esse restante da decisão em relação ao imposto e às penalidades acumuladas que impõe.

Assim continua a decisão ora recorrida:

"No que tange à acusação contida no item "b", o autuado ao transformar sucata em produto industrializado ainda que por intermédio de terceiro, configura-se como industrializador, sujeito portanto ao recolhimento do ICM - de acordo com o artigo $2 .^{\circ}$, do Decreto $50.971 / 68$, uma vez que a Laminação _. . S/A é no caso presente, simples prestador de serviços. 
Assim, todas as razões apresentadas pela defesa, não são suficientes para eximí-la da responsabilidade, "in casu", quando se trata, inclusive de falta de recolhimento de imposto.

Em face do exposto, julgo procedente o auto de infração de fls. 2, lavrado por infringência dos artigos $2 .^{\circ}$, do Decreto $50.971 / 68,39,40,37,98$ e 104, do Decreto $47.763 / 67$, e confirmo a multa imposta no total de Cr\$ ....., sem prejuízo do recolhimento do imposto na importância de Cr\$ $\$ \quad$ A multa acima, foi graduada de acordo com o disposto nos incisos I e XVI, do art. 158 , do Decreto n. ${ }^{\circ} 47.763 / 67$, modificados respectivamente pelos artigos 13 do Decreto 52666/71 e art. 18, do Decreto 52.103/69".

XIV Ora, como sabem V.Exas. a própria legislação sobre o assunto de sucata, desde o tempo do IVC, como agora do ICM, tem sido complexa, sofrido inúmeras modificações e alterações até de regime, sendo aliás o seu regime excepcional, singular e fora da regra comum, do normal entendimento dos contribuintes ou responsáveis (indústria e comércio) De resto é um assunto que dentro da honestidade científica constitui até mesmo um dos chamados temas controvertidos entre os próprios técnicos e ninguém melhor para reconhecê-lo do que os dignos Juizes desta Corte.

No caso da ora recorrente surge, inclusive, um "prius" também discutível. Não sendo ela fabricante no caso, mas apenas comenciante, essa sucata foi por ela apenas comercializada e industrializada por terceiro, por um estabelecimento fabril que não pertence à ora recorrente.

XV. Conforme esclarece um técnico e especialista em I.C.M., o Dr. Leandro G. B. Costa, em trabalho publicado na Resenha Tributária, 1969, seção I, I.C.M. n. 71 .

"De acordo com a nova regulamentação, o imposto será pago de uma só vez e sempre na sua entrada no estabelecimento industrializador, situado neste Estado.

"Revela salientar que o novo decreto estabeleceu que o tributo incidente nas sucessivas saídas deve ser "pago 
de uma só vez", e não, "pago uma só vez". Isto quer dizer que em todas as saídas em que o destinatário não for o industrializador, haverá incidência normal, simplesmente ele não será recolhido; irá se acumulando para ser pago, na última operação.

Seguindo a regra geral prevista no $\S 12$ do art. $8 .^{\circ}$ do RICM, o valor do tributo deverá ser incluido no preço das mercadorias"

XVI. Ora, em todo o contexto da legislação do IPI como do ICM, é pelo menos tese constantemente sustentada pelo Fisco a da unicidade fiscal do estabelecimento e nem sequer admite o da empresa. A conceituação do fisco gira em torno de cada estabelecimento. Portanto, se o estabelecimento industrializador não pertencia como não pertence à ora recorrente que é comerciante, entendeu ela que o imposto deveria ser pago pelo industrializador, pois se ela é comerciante e se o industrializador no caso não fosse considerado como o estabelecimento fabril e ela ora recorrente continuasse na posição negocial de comerciante, também nenhum inconveniente ocorreria porque na última operação, isto é, na da sua venda do produto, iria ela pagar, como efetivamente pagou, a totalidade do imposto que é hoje do regime de "valor acrescido".

XVII. Portanto, se o imposto, dentro desse regime excepcional e difícil foi integralmente pago pela ora recorrente, terá ela de ser punida exacerbadamente, só porque o estabelecimento industrializador não o recolheu, na entrada de seu estabelecimento, mas devolveu-lhe a sucata industrializada com suspensão do imposto para que ela viesse, como efetivamente veio, a pagá-lo, integralmente, incluindo-o no preço das mercadorias que vendeu?

XVIII. Aliás, no sistema não cumulativo ou de valor acrescido, se o estabelecimento industrializador ou a ora recorrente tivesse no ato debitado ou recolhido o imposto, teria no mesmo ato feito automaticamente o crédito - apenas lançamentos gráficos, apenas uma fantasia mecânica de débitos e créditos. $O$ verdadeiro pagamento ou recolhimento real ou efetivo só se realiza, como de fato se realizou, na venda da mercadoria. Não é possível que apenas por erro escusável de um formalismo 
sem conseqüência, seja uma tão cuidadosa empresa punida, sem nenhuma culpa. Neste sentido veja-se o aresto desta Corte, proferido pela $7 .^{\mathrm{a}}$ Câmara no processo n. ${ }^{\circ} 151.104 / 68$.

XIX. Em magnífico trabalho publicado na Revista de Direito $A d$ ministrativo vol. 103, p. 33 a 48, o Prof. Souto MAIOR assim conclui:

"Não pode a aplicação do princípio da autonomia dos estabelecimentos elidir a não-cumulatividade do I.C.M., princípio este que integra o sistema tributário da Constituição Federal. Se o contribuinte não antecipou o pagamento do I.C.M. mas o recolheu integralmente em estágio posterior do ciclo econômico, ou seja, na comercialização da mercadoria, a única exigência cabível, será, em princípio, a da mora prevista na legislação estadual pertinente à matéria, pelo atraso no recolhimento do tributo devido pelo estabelecimento industrial remetente"

XX. Mas este Egrégio Tribunal, sempre na vanguarda, já decidiu, casuisticamente:

"cancelar a exigência do tributo, uma vez demonstrado que o imposto foi pago na saída do produto industrializado, e tendo em vista a peculiar situação fiscal da utilização de cana própria por parte das indústrias de açucar, não se podia cobrar imposto relativo à entrada de matéria prima, sob pena de malferir-se o princípio da não cumulatividade do ICM, que é básico e provém da própria Lei Magna do País"

(Câmaras Reunidas, Proc. DRT - 15 - 0696/69, relator Juiz Dr. Ylves Miranda Guimarães, decisão unânime - Resenha Tributária, 4.2, 1971, n. ${ }^{\circ}$ 222).

XXI. Portanto, se no caso específico da ora recorrente, em que foi a sucata industrializada por terceiro, cujo industrializador não fez o mero lançamento simbólico (débito/crédito) ou, mesmo a ora recorrente 
não fez o citado lançamento simbólico (débito/crédito), no entanto ela recorrente o pagou integral e efetivamente, na venda das mercadorias fabricadas e acabadas com essa matéria prima. Portanto, apenas restária tão só um erro escusável (CTN art. 172, II) mas ainda erro escusável este apenas em relação a simples formalidade. Neste ponto, e "a fortiori" cabe, sem qualquer contestação, a aplicação da equidade (art. 108, IV do C.T.N.) e sob o prisma da não punibilidade, ainda protegido pelo art. 112 também do Código Tributário Nacional.

Precisamente para tais apreciações existe a boa jurisdição tributária como a do Egrégio Tribunal de Impostos e Taxas do Estado de São Paulo.

Um dos mais eminentes tributaristas e renomado comentador do Código Tributário da República Federal da Alemanha (Código este que teve a primazia entre as fontes do nosso C.T.N., conforme informa no Relatório a Comissão elaboradora), o Catedrático A. SPITALER que foi verdadeiro Chefe de Escola, precisamente ressaltando as bases fundamentais do Código, diz que como nas democracias mais autênticas, uma dessas bases é

“a farta existência da jurisdição tributária e a já há muito alcançada remoção da "barbaridade de uma pena sem culpa".

ou no original, para autenticidade:

"die starke Einschaltung der Finanzgerichtsbarkeit und die der "Unkultur einer Strafe ohne Verschulden".

A toda evidência e em face das provas juntadas nestes autos, a decisão recorrida merece ser reformada e cancelada qualquer punição. 